\title{
Disruptive Technologies and Networking in Telecom Industries
}

\section{Erik Strøjer Madsen* and Simon Preuthun Hartington}

School of Business and Social Sciences, Aarhus University, Denmark

\begin{abstract}
This article discuss' how economics of scale in supply and demand in the telecommunication industry has developed and how this has had great effect on the widespread usage and popularity of smartphones. By using this assmartphone a theoretical ground the paper looks into technical innovation in the telecommunication industry and finds significant similarities between the industry development and the literature on disruptive technology, which finds that incumbent companies are not able to react in a successful way when disruptions occur in their industry. By studying how the telecommunication industry developed around the introduction of the smartphone and looking closer into the reactions of major players such as Apple, Google, Microsoft and Nokia, we find evidence supporting the finding in the literature of an inadequate strategies among incumbent companies. Large incumbent companies focus too much on incremental innovation of their products which have a more clear short-term return and a solution of this problem is to focus less on short-term efficiency and to allow the individual researcher to follow his/her own ideas' to a larger extent.
\end{abstract}

Keywords: Networking; Disruptive technologies; Smartphone; Innovation strategies; Telecom industries

\section{Introduction}

It is well known that new start-ups firms have a high risk of bankruptcy. But in the recent years the development in industries with fast or large changes in technology, so-called disruptive technology, has also made older and large companies fighting for their survival. Schumpeter was probably the first economist to describe this threat from new entrants or new industries in a dynamic process which he labeled 'creative destruction' [1]. He argued that monopolies based on a specific technology only earn a temporary monopoly rent as new innovation would bring competition to the market sooner or later.

Since then a large literature has emerged under the headline "disruptive technology", which discusses how large and fast changes in technology is a difficult challenge for the market leading incumbent companies, which often do not manage to spot a new technology and end by losing their spot in the competitive environment to the new entrants. There are many examples in the literature from different industries such as the semiconductor industry, Tilton, the photocopier industry, Henderson and Clark, and the disk drive and mainframe computer industry, Christensen just to mention a few [24]. These studies have revealed that disruptive technologies often are introduced by companies outside the original industry structure and they introduce significantly different value propositions which have not previously been available to the market and have the potential to change the structure of the whole industry. The incumbent companies naturally form their competitive strategies on the basis of the structural environment in which they operate. However, this creates a strategic problem when the structure itself changes as they do not manage to react upon the disruptive change in technology which leads to lower demand for their products and in the end often leads to either divestment or simply liquidation of the incumbent firms Christensen [4].

The article will take a look at the latest development in the telecommunication industry where new companies like Apple and Google have entered while other companies such as Nokia and Motorola have lost their dominant position. However, some of the old telecom companies who provide the communication network like ATT, Deutsche or France Telecom are still around and in the next section we will look at some of the scale factors which are present in this industry and make the competitive condition quite different in different sections of the market. Section 3 takes a closer look at the smartphone as a disruptive new technology and explains how it changed the whole industry. Section 4 analyzes the strategies of the different actors in the industry and discusses where and how the incumbent company could react to a disruption in the technology environments. The last section concludes the study.

\section{Scale in Supply and Demand}

Economies of scale in supply and demand have always been present in the technology of telecommunication and have always created competitive challenges with though public regulation of prices and the services delivered to the customer. This was especially present when the industry emerged in the beginning of the last century with a fixed wire system to connect the costumers. The cost of establishing and operating the tele-network were mainly fixed as the communication only needs a bit of electricity to make it work, when the wire has been established. The cost structure of this technology is depicted in Figure 1 where the average cost, AC, would be ever decreasing with the size of the services. This cost structure gives rise to a natural monopoly as company A would be outcompeted by the larger company $\mathrm{G}$ due to the large cost advantages that size has for this larger company. Therefore, only one wire was offered to the consumer of telecommunication and the government stepped in and regulated the monopoly of this business often by running the telecommunication company itself in many countries.

In telecommunication there are often economies of scale on the demand side as well and this effect is illustrated in Figure 1 by the increasing average benefit, ABNET, of telecommunication services in a

*Corresponding author: Erik Strøjer Madsen, Associate professor, Department of Economic and Business, School of Business and Social Sciences, Aarhus University, Denmark, Tel: +4589486401; E-mail: ema@econ.au.dk

Received August 11, 2015; Accepted November 14, 2015; Published November 21, 2015

Citation: Madsen ES, Hartington SP (2015) Disruptive Technologies and Networking in Telecom Industries. J Glob Econ 3: 165. doi:10.4172/23754389.1000165

Copyright: (c) 2015 Madsen ES, et al. This is an open-access article distributed under the terms of the Creative Commons Attribution License, which permits unrestricted use, distribution, and reproduction in any medium, provided the original author and source are credited. 
network. This positive network effect also existed when the telephones came around a century ago. If only you have a telephone, it is not of much use for you, but as more people in your network obtain a phone, the benefit increases for you as for everybody else so the average benefits from the consumers phone increase with the size of the network. This is a special feature of network services and does not hold for a private good which are consumed by the individual and where the average benefit is constant or decreasing with the amount of the services.

While the phone wired by a fixed line is about to go into history, the new mobile technology has the same cost structure and network effects. The establishment of a mobile network is cheaper than the fixed wire so more tele companies compete to offer their services in a given area but their services and prices are still regulated by the public authorities. However, with the smartphone a lot of other services beside voice communication become available to the consumer as it provides access to the internet. This makes it possible to transfer most of the services developed for the PC users to the mobile phone and this extends the industry with a lot of other service providers and transforms its structure as pictured in Figure 2 from a "traditional industry structure" to a "new industry structure" with all the new service providers and developers of these applications for the new extended marketspace.

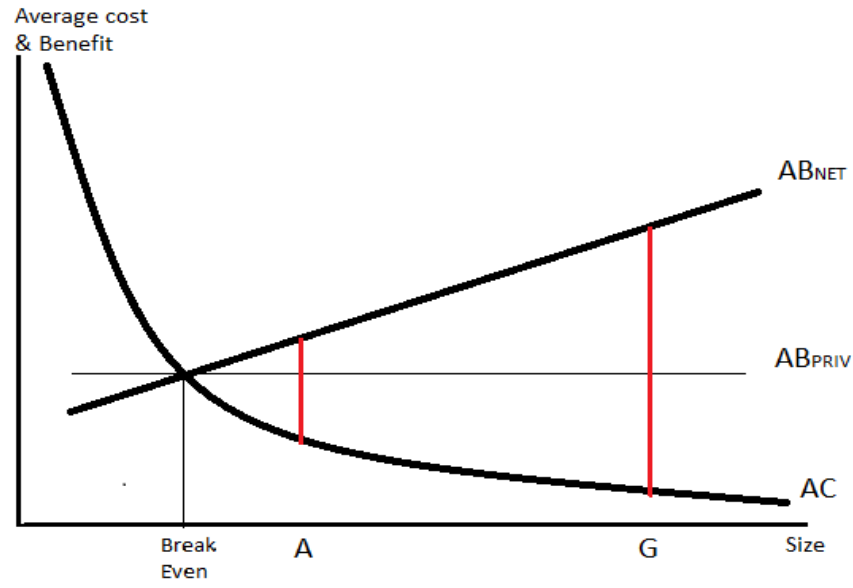

Figure 1: Economies of scale in supply and demand of telecommunication.
Many of these new services also have a scale factor on both the supply and demand side. This is the case for services facilitating the consumers social networks like Facebook, Twitter, Instagram, Snapchat and different dating sites just to mention a few. The costs to provide these services are almost fixed and not related to the number of users. The benefit, on the other hand, increases for the customer when the number of users increases and covers more of their social network. This contributed scale effect on the demand side from all the service providers contributed to the explosive increases in the demand for the smartphones which in a short period overtook the main market for mobile phones, as it facilitates a lot of social network tasks beside voice communications.

All the new social network services have the potential of a high profit as illustrated in Figure 1 by the red line, if they grow beyond the break-even level, as the average cost will decrease and the average network benefit will increase. However, a lot of the new start-ups never reach the break-even point and therefore break down by going into bankruptcy or reconstruction, but for those who make it, at least two effects reduce the monopoly elements for these new service providers. First, protection by patenting of these services is difficult so it is easy to develop new services covering a close and/ or related need in the social network. These close substitutes reduce the monopoly power of the network services and the profit from it, as the demand shrinks. Facebook's competition from the launch of Instagram in 2010 is an example of the threat from new entries in this industry and Facebook's acquisition of Instagram in 2012 an example of how to handle new entrants. Second, most social networks are geographically constrained which means that the network effects only offer the conditions for a local monopoly. This explains why China can have its own version of Facebook called WeChat, as there is not much network interaction across national or language boarders. This local constraint also holds for a lot of the GPS-based services like the 'find' apps that help finding the nearest bus, train, bar or people you want to meet for some reasons.

An important technical constraint in the development of the smartphone is the operating system which compared with the PCoperating system has to handle the communication via the touchscreen and phone. The service providers have to develop their application software compatible with the operating system and as an app cannot easily be switched to another operating system, there is a lock-in effect where the operating system determinates the number and kind of appservices available for the consumer. Of cause, it is more attractive to
Traditional industry structure Before the rapid growth of mobile data

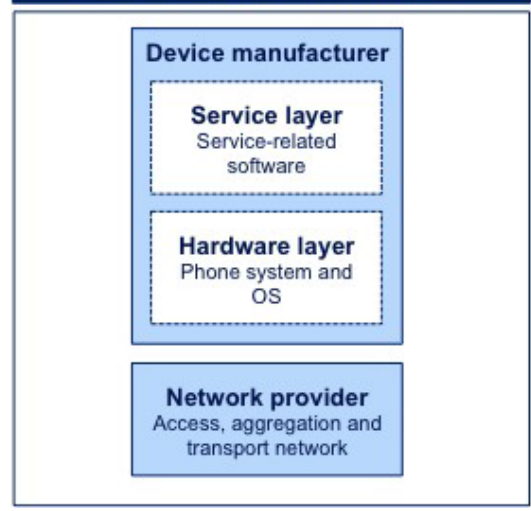

New industry structure

After the rapid growth of mobile data

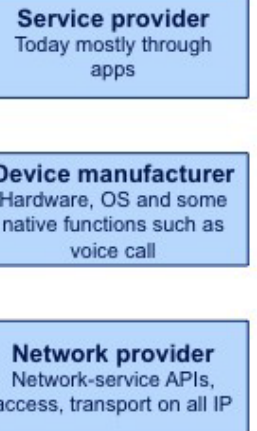

Figure 2: Structural changes in the telecom industries. 
develop apps to an operating system with many users, as it creates more costumers for the app services. This compatibility creates huge scale effects for an operating system on the demand side and together with the fixed cost structures; market size then becomes a crucial competition parameter and an entry barrier. Figure 3 pictures how this intense competition has shifted the market share for operating systems to smartphones in the period after the introduction of Apple's smartphone with the iOS operating system in 2007. Google introduced their operating system, Android, in 2008, and 3 years later it had managed to captured half of the market at the expense of Nokia's operating system, Symbian, which in the period was reduced from a dominant and market leading position to a market share below 20 percent in 2011. In 2014 only Microsoft was left among other systems with their Windows version. The next section will take a closer look at this development of the technology.

\section{Disruptive Technology in Telecom}

Change in technology and innovation has always been central in the analysis of productivity and economic growth where it has been treated as an exogenous factor outside the control or modelling of growth. Schumpeter builds part of this gap by focussing on the role of innovation and the individual entrepreneur's central place in the competition and restructuring of the industries where new innovation can create whole new industries and replace what already existed [1]. He discusses the economic incentive of a high monopoly rent for the entrepreneurs to create new innovation, but he does not put this innovation activity into a deliberate management strategy.

Tushman and Anderson were among the first to see that companies need a strategy to manage innovation if they want to stay at the frontiers of competition in their industries. They believe that the organizations and strategies used by these companies are formed by the environment of innovation, which normally progresses through long periods of incremental adoption of new innovations [5]. Therefore, the incumbents also adapt a strategy of small adaptions in technology and design as they develop. However, in many industries these periods of small changes are superseded by brief periods which change the whole industry-often known as a disruptive technology. Companies that do not survive are not aware of this break in technology and they often try to adapt to disruptions by only changing their organization and technology incrementally.

It is therefore important for the companies to be able to spot this break in technology so they can prepare themselves against the competitive consequences. A large body of literature has dealt with this issue under the label disruptive technologies, and for a survey of this literature [6]. One of the insights from this literature is that most disruptive technologies actually co-exist side by side with other technologies for quite some time. It is often a period where they are underperforming the existing technologies before they are given a facelift, which makes them the preferred dominant design and hence able to outcompete existing technologies. The time lag in the breakthrough of the technology is also the circumstances which make it possible to predict the competitive effects of a disruption and for the companies to adapt their strategy accordingly, so they can eliminate the consequences or take advantage of it. This is also what happened in the telecom industry when the smartphone was introduced in 2007 and we will take a look at this development.

Often the disruptive changes in technology are not due to one innovation but a whole range of innovations within the field and where all have to be present to make the whole system work. This is also the case with the smartphone which draws on a range of different breakthroughs in technology. The data-bearing broadband was probably the first of these innovations with its ability of bringing the internet to the mobile phone and with that all the networking possibilities. There has been some data-bearing networks available already from the early 1990s which were used for SMS communications and which became quite popular and generated a considerable amount of income for the tele companies. But it was first with the introduction of the $3 \mathrm{G}$ technology at the turn of the century that the network became strong enough to bear music, pictures and movie formats, which really made it usable as a mobile device for pleasure, information search and network communications.

The governments were probably the first to see how this new technology could improve network speed and capacity significantly and also how they could cash in on it. So, early in the new millennium most governments issued licenses to operate the new $3 \mathrm{G}$ broadband by launching bid-auctions, contrary to earlier licenses, which had been allocated mainly to incumbent companies. The first movers were the UK and Germany which auctions in 2000 generated more than USD 80 billion or seven times more than expected and left the bidding companies heavily indebted as they also had to pay for the upgrading of their network. The total investments in 2000 were more than three times higher than the accumulated total investments from 1990 to 2000 in this industry OECD [7]. Most other European countries followed in the coming years, but despite these massive investments in capacity upgrading there were no real impact on the usage of the mobile data capacity available which can be seen in Figure 4.

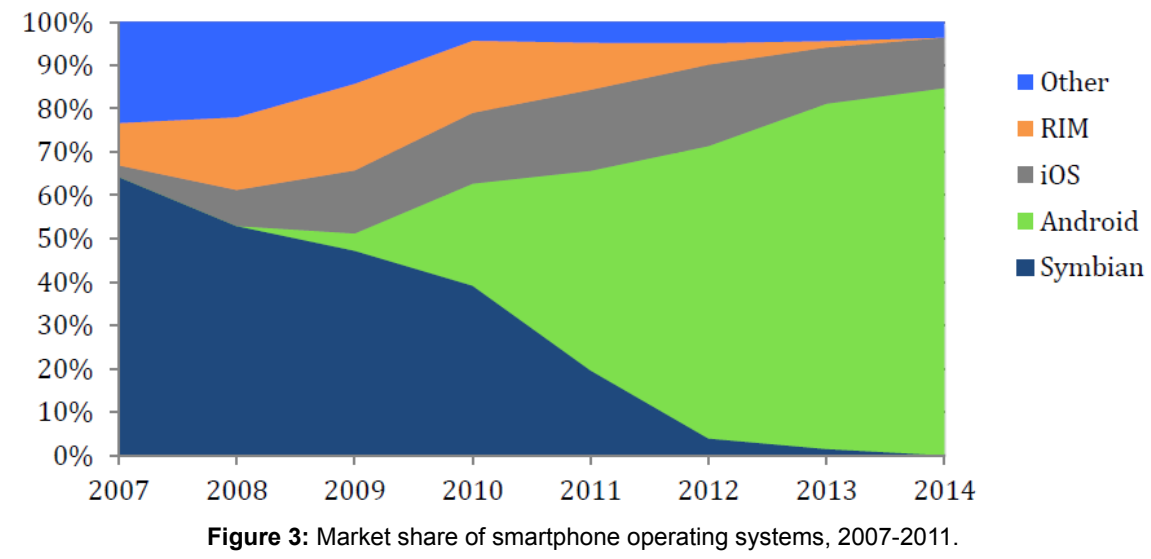




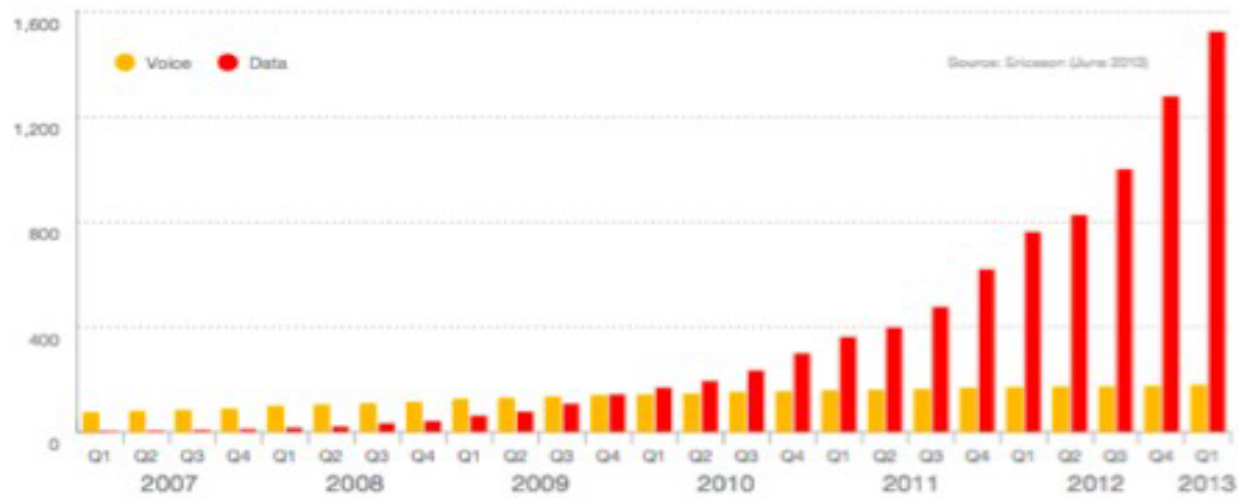

Note: The communication is measured in petabyte.

Figure 4: Communication traffic in global mobile networks, 2007 - 2013

The figure clearly illustrates that even though the teleoperators offered the services and the consumers increasingly adopted $3 \mathrm{G}$ mobile devices, they were not embracing and using the data-driven technology until 10 years later. The first movers had probably overestimated the income that they could generate from the G3 licenses, as they in the following years had to write off large amounts of their investment and as a result, their share prices tumbled. Furthermore, the prices at the auctions fell drastically so latecomers in 2001 only paid $20 \%$ of the price per capita for a license compared to the UK and German licenses. However, some of the price differences were also due to different conditions at the auctions, se Klemperer [8].

What really made the difference in data traffic was the introduction of Apple's version of a smartphone, the iPhone, in 2007. While the iPhone offers features that were standard in other smartphone devices, it was at the same time significantly different, as it introduced two new key technologies that make the breakthrough, a large touch screen for video and web usage and an extremely simple user interface through its iOS operating system. This made it easy to access iTunes music, video services and allowing for easy scrolling and a zoom function by the use of two fingers. It also contained a full keyboard on the touchscreen, which allowed for handling emails and other communications, but most important was a browser that was based on personal computer standards rather than a browser that was rewritten for a mobile device. The new personal browser allowed access to all the information available on the internet, something the competitors had not been able to offer. Steve Jobs, the founder and president of Apple, emphasised the disruption nature of the iPhone when he presented it at a launch ceremony, where he said: 'Every once in a while a revolutionary product comes along that changes everything'.

The earlier mobile devices were not user-friendly and could not take advantage of all the new possibilities in the G3 mobile broadband, but the iPhone contained the new key technologies which made the breakthrough. The touchscreen itself had been around for some years and was first introduced on a mobile phone by IBM in 1993. Also Palm used a kind of touch screen in their models, where the user had to use a special pin for operating, while Blackberry's smartphone from 1999 was featured with a small but full physical keyboard. None of these devices were though user-friendly, as the browser and operating system offered limited possibilities. Google was fast to catch up on the new development in the mobile devices which allowed for access to the normal internet; an area where Google has the highest market share for search engines. Google introduced its own operating system Android in 2008 just one year after Apple. It had the same capabilities as Apple's iOS operating system, and Google later had to fight with Apple in a patent dispute, as Apple claimed that Android broke several patents behind the iOS operating program. However, Android was quick to catch up on Apple's market share for operating systems as seen in Figure 3. Just two years after its lunch it had surpassed Apple's market share and in 2014 Android actually hold 85\% versus only 12\% for Apple. At that time Android had also attracted more apps than iOS - a new market area, which dramatically extend and changed the services delivered by this industry. How do the incumbent companies in the teleindustry adapt to this disruptive development? Next section will take a closer look at this development and try to relate to the strategies of the companies.

\section{The Destruction and the Strategies}

The disruptive technology has affected and restructured the telecommunication industry and we will now look at how the main player in the industry responded to the disruption. Figure 2 divided the companies into two groups, those who operate and provide the network and those who manufacture and supply the mobile devices and they became affected quite differently and they also react differently to the disruptive technology.

For the network provider it was quite clear what would happen as the government offered the new G3 licenses and for the first time in some countries invited companies to bid for a license on an auction basis. If the incumbent telecompanies want to stay in business they have to walk away from the auction with a license. That is probably also one of the reasons why the first auctions in the UK and Germany ended with very high bids and made the telecompanies heavily indebted as a result. This affected their profit in the following years as shown in Figure 5, where Deutsche Telecom and the UK based Vodafone show negative operating profit margins after a large write-down of their investment in the G3 network. Vodafone acquired the largest available $3 \mathrm{G}$ license in the UK in 2000 and at the same time it acquired Mannesmann, a large German mobile operator. The acquisitions doubled its size, but also the potential losses from the G3 licences. The two American operators AT\&T and Verizon and the Spanish Telefonica were not affected by the European allocation of licenses by auctions. However, it seems that the operating margins have been falling over time from above 20 to below 20. This can be a result of an intensified competition, but as the 

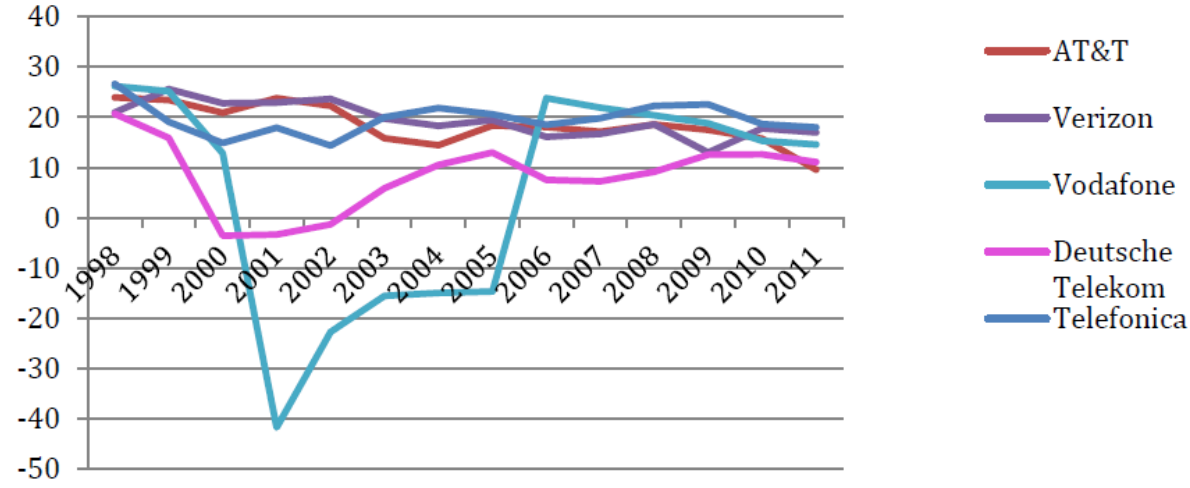

Note: Operating profit measured in percentages of total revenue

Figure 5: Operating profit margin for 5 mobile operators.

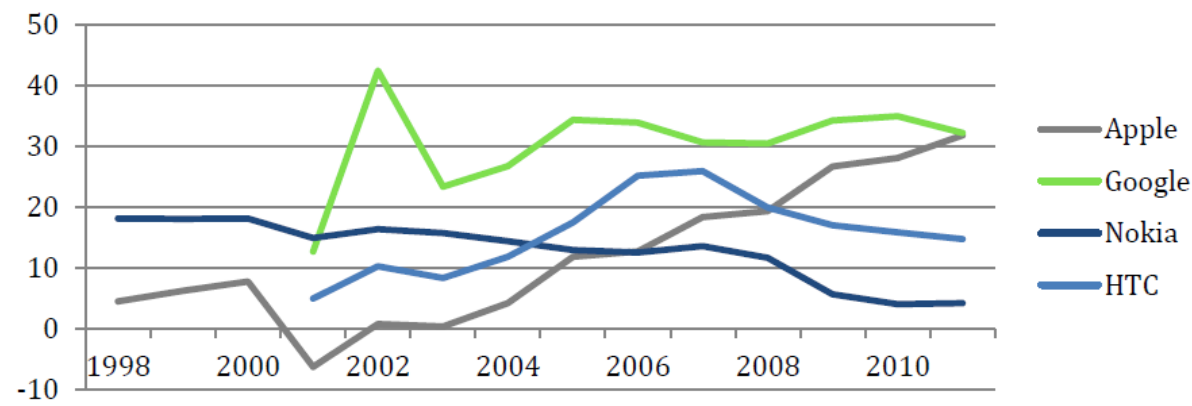

Note: Operating profit measured in percentages of total revenue

Figure 6: Operating profit margin for 4 competitors in the smartphone market.

operators have to have their rates approved by the teleauthorities, it can be a result of changes in this regulation as well.

On the market for mobile phones there were no price regulations and the situation changed when Apple entered the market in 2005 with a breaking new smartphone with a clear competitive advantage compared to the smartphones already on the market. Nokia was the main player on the market of mobile devices at the time with a market share above $40 \%$, but the share of smartphones were still close to zero. Nokia has made an agreement with Ericsson and Motorola in 1998 to use its Symbian as the operating system for smartphones, and it launched Nokia 9000 Communicator which contains a small but full keyboard for interface communications. However, as already shown in Figure 3, the iOS and later Android quickly captured the main share of the market at the expenses of the smartphones with other operating systems. This market development was mirrored in the financial performance of the companies as pictured in Figure 6. Nokia's operating profit margin dropped from about $20 \%$ to just $4 \%$ in a few years whereas Apple's profit in the same period scored to more than $30 \%$. The competition among the large number of mobile phone manufacturers did put a pressure on their profit, which the development in HTC's operating margin reflects.

The suppliers of operating systems all choose different strategies in their marketing. Apple, as a first mover, did choose a closed strategy where it did not license iOS to other companies. Google, on the other hand, chose to offer Android for free to other companies. Of course, Google has had a fat profit of about $30 \%$ in the period, but why offer it for free? The main reason for this is probably that it was used to free-ware as it already offered its search engine for free, and its main income came from internet advertising. By offering Android for free and thereby having ownership to the operating system, it would be easier to protect its share of the internet advertising, when the different services move from the PC to the mobile devices. It seemed to be a profitable strategy as the internet advertising increased dramatically in the following years mainly at the expenses of newspaper advertising (Figure 7). According to Wikipedia, Google's revenues from ads were USD 42.5 billion in 2012 which amounted to $40 \%$ of the global internet advertising of USD 105 billion according to Warc - Advertising best practice, evidence and insight. However, other companies want a piece of the cake, and recently Facebook made its entrance on this market, and it probably has an advantage compared to Google, as it has more personal information of the users and thereby can tailor the advertising to the most relevant costumers.

By offering Android for free, Google quickly conquered the main market for operating systems and today still holds a dominant position. But due to large-scale effects in both supply and demand as discussed earlier, Google has a competitive advantage over Apple as shown in Figure 1 with the company size of A and G. So why has Apple not switched to Android as it is a free software and it therefore could save the cost of offering the iOS? Apple has chosen a branding strategy to make Apple products unique in design and capabilities so it could ask for a price premium in the market. This strategy has paid off in recent years and Apple overtook the position as the most valuable company 


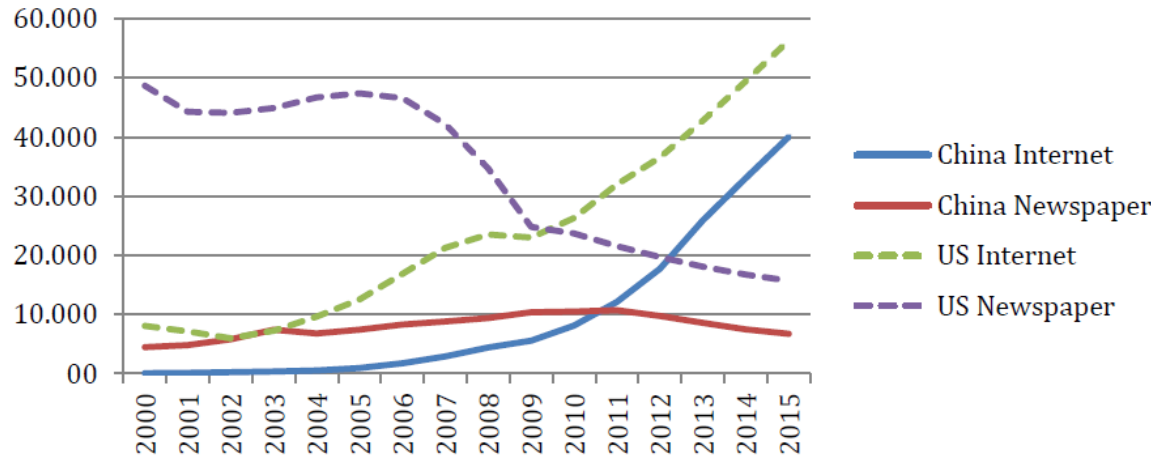

Note: Advertising expenditure measured in million USD PPPs current prices.

Figure 7: Advertising spending in media, billion USD.

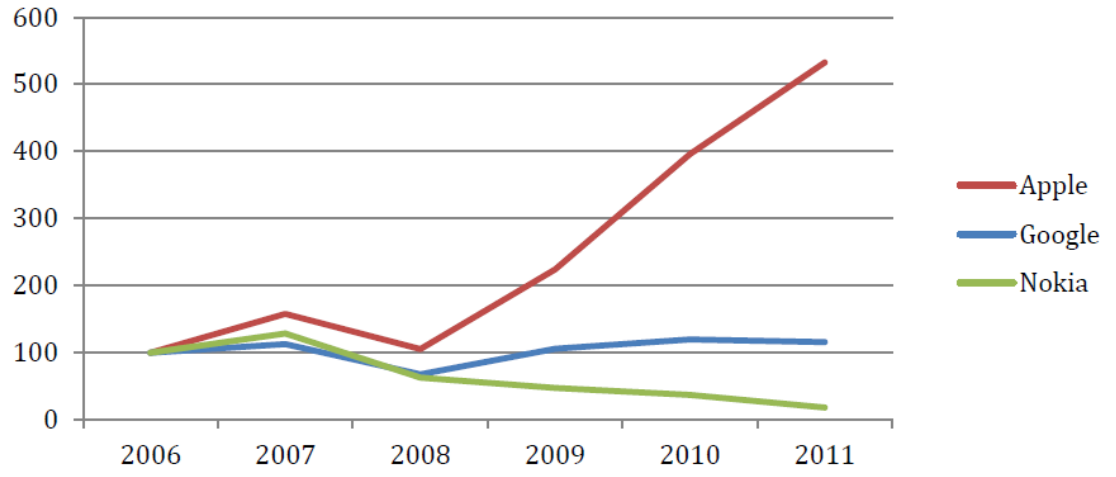

Note: Index of the stock price with base in 2006.

Figure 8: Stock prices for 3 competitors in the smartphone market.

in the world. The decision not to outsource the operating system is probably essential as it makes it possible to integrate the different hardware in a unique way and easily expand the range of services. However, for iPod and iTunes Apple choose open systems which made iTunes grow to the largest online music store in a few years; a position it still enjoys. So the closed strategy also has its cost in terms of the potential market size of the different services.

What about the incumbent companies in the industry, how did they react to the disruption? The disruption literature is in general very clear when it comes to incumbent reactions to possible disruptive products - they never really manage to come up with good solutions [4,9-11]. Nokia, the real industry leader with sales of more than $40 \%$ of mobile phones, is a classic example of inadequate response as they tried more or less only with incremental improvements of their product. Nokia did not acknowledge the importance of the new technology and choose to stick to their own operating system, which at the time was not at all geared to the smartphone market that Apple had introduced. This made their first products, that were supposed to be responses to the iPhone launch, perform very poor compared to their smartphone competitors. It became clear that Nokia had chosen to focus a lot on hardware upgrades while they generally reacted late in terms of both new product launches and software updates, which made them loose a lot of ground on the important APP marketplace for smartphones, as they had completely underestimated the new technology. This destruction process is also visible when looking at their share prices in Figure 8. The price of Nokia's shares dropped with $80 \%$ in a few years whereas Apple's increased by a factor 5 . Nokia later switched to Microsoft's operating system, and in 2013 Microsoft acquired Nokia's mobile division.

Microsoft, once the most valuable company measured at market price, is another classic example of a competitor that did not manage to react competitive when the capabilities of a PC started to move onto mobile phones. With the launch of the Windows operating system for mobile phones in 1996 and the subsequent launch of a phone with a touchscreen, Microsoft was indeed a player on the market for operating systems and mobile phones. Combined with the fact that Microsoft spends billions of dollars in the 90s on introducing their own search engine, MSN, it seems like Microsoft had all the prerequisites to conquer the market in the same way as Google did. Microsoft later went on to buy Nokia and made them deliver the hardware for their phones, and they also introduced the concept of Microsoft Retail Shops, which was probably an attempt to copy the branding strategy of Apple. With a market share of only about 3\% in 2014, where Microsoft actually also started to install Android on its Nokia phones, this case does indeed show that deep pocket is not enough in a market with much innovation and strong network effects, which makes it extremely difficult and expensive to enter (Figure 1).

This case with Google and Apple also underlines one of the key statements in the literature on disruption, that disruption normally is introduced by companies outside the industry itself. While Google 
entered the industry to protect its business in search engines, it is interesting to look into what motivated Apple to enter? First of all, Apple was in a related industry with much of the same technology. But more importantly, it moved into the music entertainment industry when launching the iPod and iTunes in 2001 and 2002. Mobile phones containing music and photographic facilities were introduced and this was a threat to Apple's large market for music entertainment. Steve Jobs, the founder and CEO of Apple, was creative enough to see this development and push the company's innovations into the telecom industry. This move was also the one that really pushed the value of the company ahead of everyone else.

What can we learn from this case about how do companies survive a disruption? The case provides some clear answers to this question. The incentive for a potential profit in the future is probably the most important motivation for any response or entry, which the example of both Google and Apple illustrates - a factor already mentioned by Schumpeter. Further, the examples with Microsoft and Nokia shows, that deep pockets do not seem to be neither important nor a precondition for success in markets with a high level of innovations. Both Microsoft and Nokia clearly had the means to finance whatever initiative they wanted to launch, but clearly they do not manage to address the technology gab in time. So another important question is what the incumbent companies can do to address this lack of ability to develop breaking new technologies?

The examples clearly show that the organizations and management of innovations is important. In large companies the innovations are developed in a special research department where the organization is focused on performance and efficiency which is easily measured by short-term improvements on the market for their products. They therefore focus on the development of useful incremental innovation or adaption of the products they already have on the market and which have a clear and measurable return rather than allocate resources to some disruption technologies which have a much higher risk and unpredictable return. The example with timing of the investment in the G3 network clearly shows how risky this kind of innovation is and that a large research department may not be willing to take that risk. That is what Steve Jobs did, but he did not have to ask anybody else.

This indicate that the governance decision-making autonomy and the level of creative freedom in R\&D and business development department is essential for whether or not companies are able to be on the forefront of product development and successfully respond to disruptions. A possible solution could be to give the researchers more individual freedom within the department so that they can and are allowed to allocate more of their time to their own creative ideas and projects which have no short-term measurable outcome. The management also have to accept a higher risk, where the company may end up launching some of the new products at the forefront of innovation and possible disruption, but where their market performance do not pay off the full cost of development. A lot of organizational adaption could probably allow for this. One solution could be to focus less on the individual performance and more on research teams, and then form some teams which focus on long-term strategic developments within their business and where the measurable output is not the success criteria. Lastly, it could simply be an idea to give the researchers some free hours per week where they can work on some promising projects of their own or in teams.

Often the most creative researchers end out by leave the companies with their ideas because they cannot get through within the company. A less strict working environment could reduce this problem to the benefit of the company. However, workers with good ideas could always leave the company and try to make it on their own or in another company. To handle this appropriation problem the company could set up a seed company to facilitate the entrepreneurship with capital and other facilities and thereby get a share of the pie if any of the products succeed.

How to provide more evidence on an appropriate strategy? The road to follow could be to bring this area of research from the casebased evidence to evidence based on a larger sample of facts. This should include evidence of the organization of the development department with a focus on the independence of the individual researcher and to which extent the researchers are allowed to follow their own ideas and how their performance is measured. However, this is not an easy task and the main problem is probably how to define a disruptive innovation. As the disruption often consists of several innovations which emerge at different times, it is difficult to define the disruption based on innovation or patent data. An alternative approach is to define it by the disruption it creates in the industry structure. This could be done by looking at short-time shifts in the market shares, as if a major market share shifts from the incumbent firms to new entrants in a short period or between the incumbent firms. Of course, this makes it tricky to analyze the performance related to disruption, but it still allows for studying the innovation strategies of the firms.

\section{Conclusion}

By using the telecommunication industry as an example this study highlighted how innovation and technological disruptions has the power to make large structural and competitive changes within an industry. By looking closer at the introduction of the smartphone we show how an industry that is faced with a disruption opens for new entrants, which in a matter of a short time-period forced financial strong and market leading incumbent companies to restructure and/ or leave the industry.

This article also looks closer into how scale effects in supply and demand had and still plays an important role in the telecommunication industry and how the nature of scale effects has contributed to a faster introduction of the disruptive new technology for the service providers in this industry. The large scale effects also made it difficult for the incumbent companies to strike back after the introduction of the disruption, which is much related to the nature of the industry and technology. However, the incumbent companies was clearly also inadequate to handle these large changes in the technology environment, which is highlighted by the type and magnitude of companies that was outcompeted.

The innovation strategies of the incumbent firms have therefore been inadequate to handle these large changes in the technology environment and even companies with deep pockets do not manage to catch up in this industry due to the large-scale effects. Probably the large incumbent firms are focused too much on incremental innovation of their products which have a more clear calculated short- term return and a suggested solution of this problem is to focus less on short-term efficiency and allow the individual researcher to follow their own ideas to a larger extent. However, we clearly also need more knowledge of the innovation process in the large research departments concerning the creation of disruptive technologies.

\section{References}

1. Schumpeter JA (1942) Capitalism, Socialism and Democracy.

2. Tilton J (1971) International diffusion of technology: The case of semiconductors 
Citation: Madsen ES, Hartington SP (2015) Disruptive Technologies and Networking in Telecom Industries. J Glob Econ 3: 165. doi:10.4172/23754389.1000165

Page 8 of 8

Brookings Institution Press, Washington

3. Henderson R, Clark K (1990) Architectural Innovation: The Re configuration of Existing Product Technologies and the Failure of Established Firms. Administrative Science Quarterly 35: 9-30.

4. Christensen C (1997) The innovator's dilemma - when New Technologies Cause Great Firms to Fail. Harvard Business School, Boston.

5. Tushman M, Anderson P (1986) Technological Discontinuities and Organizational Environments. Administrative Science Quarterly 31: 439-465.

6. Hartington S, Søndergaard K (2014) Disruption of mobile data.
7. OECD (2005) OECD Communication Outlook 2005. OECD Publishing.

8. Klemperer P (2002) How (Not) to Run Auctions: The European 3G Telecom Auctions. European Economic Review 46: 829-845.

9. Cooper A, Schendel D (1996) Strategic Responses to Technological Threats. Business Horizons 19: 61-70.

10. Chen MJ (1996) Competitor analysis and interfirm rivalry: Toward a theoretical integration. Academy of Management Review 21: 100-134.

11. Hill C, Rothaermel F (2003) The performance of Incumbent Firms in the Face of Radical Technological Innovation. Academy of Management Review 28: 257-274. 